\title{
Modifikasi Motor Bakar 4 Langkah Bahan Bakar Bensin Menjadi Biogas: Aplikasi Untuk "Engine Test Bed"
}

\author{
Wishnu Wijayanto ${ }^{1^{*}}$ dan Eny Apriyanti ${ }^{2}$ \\ ${ }^{1}$ Departmen Teknik Kimia, Universitas Diponegoro \\ Jl. Prof. Soedarto, Tembalang, Semarang, Jawa Tengah 50275, Indonesia \\ ${ }^{2}$ Departement Teknik Kimia, Universitas Pandanaran \\ Jl. Banjarsari Barat No.1 Tembalang, Semarang, Jawa Tengah 50268, Indonesia \\ Email :wishnuwijaya@che.undip.ac.id
}

\begin{abstract}
ABSTRAK
Biogas merupakan salah satu bahan bakar non fosil bersifat renewable (terbarukan) yang dapat dijadikan bioenergi alternatif. Biogas memiliki konsentrasi gas metana (CH4) yaitu 50-75\%, gas karbon dioksida $\left(\mathrm{CO}_{2}\right) 25-50 \%$, gas nitrogen $\left(\mathrm{N}_{2}\right) 0-0,3 \%$, gas hidrogen $\left(\mathrm{H}_{2}\right) 1-5 \%$, gas hidrogen sulfida $\left(\mathrm{H}_{2} \mathrm{~S}\right)$ 0,1-2 \% dan gas oksigen $\left(\mathrm{O}_{2}\right)$ 0,1-0,5\%. (Hambali, 2007). Untuk dapat menggunakan biogas sebagai bahan bakar motor bakar pada mesin bensin generator 4 langkah 1300 (watt) dilakukan modifikasi pada : kelonggaran katup isap dan buang, injektor venturi pada karburator dan menaikkan rasio kompresi 9,2 - 9,3. Pada pengujian dihasilkan torsi maksimum 4,1 (Nm), Temperatur $490^{\circ} \mathrm{C}$ pada pembebanan 1000 (watt).
\end{abstract}

Kata kunci : biogas; gas metana; modifikasi; pembebanan; torsi

\section{PENDAHULUAN}

Energi merupakan salah satu permasalahan utama dunia. Kebutuhan energi di dunia hingga saat ini cenderung bergantung pada bahan bakar fosil. Konsumsi bahan bakar fosil dapat dilihat dari banyaknya penggunaan mesin industri dan transportasi penunjang perekonomian dunia yang menggunakan minyak bumi sebagai bahan bakar penggeraknya. Indonesia merupakan salah satu negara yang sedang menghadapi persoalan energi yang serius akibat ketergantungan yang sangat besar terhadap bahan bakar fosil. Hal ini terbukti dengan adanya kebijakan pemerintah dalam konversi minyak tanah ke gas (LPG).

Indonesia memiliki potensi untuk melakukan pengembangan energi alternatif. Sebagai contoh dengan memanfaatkan limbah biomassa yang sangat melimpah dari sektor pertanian dan peternakan untuk dijadikan bioenergi sehingga masyarakat dapat memperoleh energi yang relatif lebih murah dan dampak lingkungan lebih bersih.

Biogas merupakan salah satu bahan bakar non fosil bersifat renewable (terbarukan) yang dapat dijadikan bioenergi alternatif (Mitzlaff, 1988). Biogas adalah gas yang dihasilkan oleh bakteri apabila bahan organik mengalami proses fermentasi dalam reaktor (biodigester) dalam kondisi anaerob (tanpa udara). Pemanfaatan biogas mempunyai beberapa keunggulan jika dibandingkan dengan BBM (bahan bakar minyak) yang berasal dari fosil diantaranya biogas mempunyai sifat yang ramah lingkungan dan terbarukan. Bahan bakar fosil yang pembakarannya kurang sempurna menghasilkan $\mathrm{CO}_{2}$ yang merupakan salah satu gas penyebab pemanasan global. Biogas memiliki konsentrasi gas metana $(\mathrm{CH} 4)$ yaitu $50-75 \%$, gas karbon dioksida $\left(\mathrm{CO}_{2}\right) 25-50 \%$, gas nitrogen $\left(\mathrm{N}_{2}\right) 0-0,3 \%$, gas hidrogen $\left(\mathrm{H}_{2}\right) 1-5 \%$, gas hidrogen sulfida $\left(\mathrm{H}_{2} \mathrm{~S}\right) 0,1-2 \%$ dan gas oksigen $\left(\mathrm{O}_{2}\right)$ 0,1- 0,5\%. (Hambali, 2007) 


\section{METODOLOGI}

\section{Biogas untuk bahan baku pengujian mesin.}

Komposisi biogas yang dihasilkan dari berbagai digester anaerobik sangat tergantung pada jenis bahan baku yang digunakan. Biogas terdiri dari gas metana, karbon dioksida, hidrogen sulfida dan amonia. Komponen - komponen lainnya yang ditemukan dalam kisaran konsentrasi sangat kecil (trace element) antara lain senyawa sulfur organik, senyawa hidrokarbon terhalogenasi (halogenater hydrocarbon), hidroden, nitrogen, karbon monoksida dan oksogen. Disamping juga mengandung uap air, partikulat dan kadang juga mengandung senyawa volatin. (Monnet, 2003). Komposisi biogas dapat dilihat pada Tabel 1.

Tabel 1 menunjukkan bahwa komposisi biogas sangat bervariatif dengan komposisi utama gas $\mathrm{CH} 4$ berkisar antara 40 hingga $75 \%$ dan gas CO2 antara 50 - $60 \%$ volume. Disamping itu biogas mengandung beberapa gas pengotor antara lain gas $\mathrm{H} 2$ antara $0-5 \%$ volume, $\mathrm{H} 2 \mathrm{~S}$ antara $0-<5 \%$ volume dan $\mathrm{O} 2$ antara $0-<2 \%$ volume.Informasi lain yang belum terdapat pada tabel diatas adalah bahwa biasanya biogas juga mengandung uap air dengan tingkat kejenuhan antara 5 hingga $90 \%$, sehingga perlu untuk dipertimbangkan pemurniannya jika dianggap mengganggu pada berbagai penggunaan lebih lanjut.

\section{Modifikasi mesin generator listrik 4 langkah 1300 watt}

Mesin generator listrik ini dilakukan modifikasi di beberapa bagian sesuai kebutuhan untuk bahan bakar gas antara lain: 1). Setup katup hisap 0,35 (mm) dan buang 0,3 (mm), 2). Memodifikasi karburator mesin menjadi berfungsi sebagai nosel gas (Gambar 1). Dengan mengeluarkan nosel jet inlet bensin kemudian ditutup atau disumbat dan pemasangan nepel untuk input gas dari bodi luar sampai leher venturi asli. 3) Membubut kepala silinder setebal 0,4 (mm) untuk menaikan rasio kompresi menjadi 9,2 - 9,5. 4) Laju alir biogas yang diijinkan untuk umpan bahan bakar adalah 0,3-0,6 (liter/ menit). Hal ini untuk mencegah mesin kekurangan maupun kelebihan bahan bakar sehingga mesin menjadi sukar/tidak hidup (Lin, 2005).

\section{Pengujian unjuk kerja mesin generator.}

Pengujian mesin generator yang telah dimodifikasi untuk bahan bakar biogas menggunakan sistem pembebanan secara elektris yaitu membebani generator dengan dinamometer listrik. Voltase output yang digunakan 220 (V), tetap menggunakan sistem governor yang ada

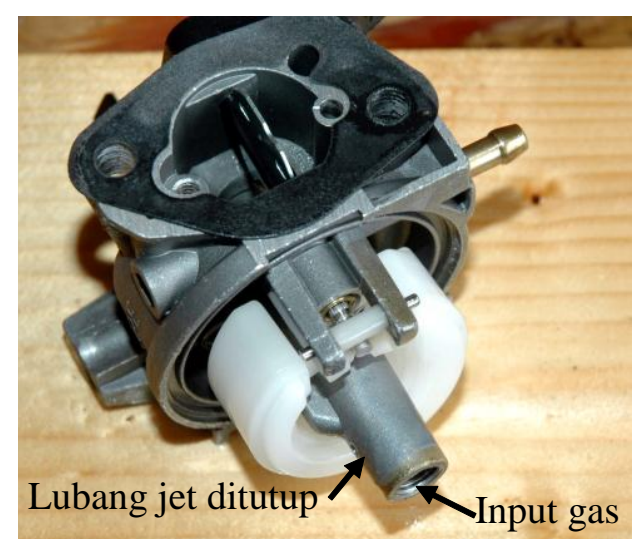

Gambar 1. Modifikasi karburator.

Tabel 1. Komposisi biogas

\begin{tabular}{ccccccc}
\hline & & \multicolumn{5}{c}{ Komposisi (\% Volume) } \\
\cline { 3 - 7 } Komponen & Satuan & $\begin{array}{c}\text { Anonim, } \\
2010\end{array}$ & $\begin{array}{c}\text { Hambali } \text { al., } 2007 \\
\text { annnet, }\end{array}$ & $\begin{array}{c}\text { Monneryati, 2006 } \\
2003\end{array}$ & $\begin{array}{l}\text { Pellerin et al., } \\
1988\end{array}$ \\
\hline (CH4) & $\%$ Vol & $55-75$ & $50-75$ & $55-75$ & $40-70$ & $50-60$ \\
$\mathrm{CO} 2$ & $\%$ Vol & $25-45$ & $25-40$ & $30-45$ & $30-60$ & $50-60$ \\
$\mathrm{~N} 2$ & $\%$ Vol & $0-0,3$ & $<2$ & $0-0,2$ & - & - \\
$\mathrm{H} 2$ & $\%$ Vol & $1-5$ & $<1$ & 0 & $0-1$ & - \\
$\mathrm{H} 2 \mathrm{~S}$ & $\mathrm{ppm}$ & $0-3$ & $<2$ & $<5$ & $0-3$ & $<1$ \\
$\mathrm{O} 2$ & $\mathrm{ppm}$ & $0,1-0,5$ & $<2$ & - & - & - \\
\hline
\end{tabular}


untuk menjaga kestabilan output generator. Pada output gas buang dipasang termokopel untuk memonitor kondisi suhu gas buang hasil pembakaran. Variabel pada pengujian ini adalah Torsi, Beban, Temperatur gas buang. Bahan bakar yang digunakan pada pengujian ini menggunakan biogas yang telah dipurifikasi.

\section{HASIL DAN PEMBAHASAN}

\section{Bahan bakar untuk pengujian}

Biogas yang dijadikan input untuk uji generator diambil dari biogas yang telah mengalami purifikasi. Biogas ini diambil setelah 15 hari dari proses pembuatan, komposisi gas metana pada biogas tersebut (Tabel 2).

Dari hasil uji komposisi dapat dilihat bahwa $\mathrm{CH}_{4}$ yang dihasilkan dari biogas plant rata-rata dapat menaikan kemurnian $30 \%$, sehingga didapat gas metana dengan kandungan $75 \%$ mol. Gas metan ini sudah memenuhi persyaratan untuk bahan bakar uji generator. Gas metana mulai disimpan kedalam tangki penyimpan setelah umur 15 hari. Gas ini dipanen setiap hari selama 15 hari untuk bahan bakar pada pengujian mesin generator.

\section{Uji mesin generator 220(V)/1300 (watt)}

Pengujian mesin generator ini menggunakan dynamometer listrik dengan parameter yang dapat terukur antara lain variasi beban dan torsi, pembebanan dimulai dari beban 200 watt selama 5 menit kemudian kenaikan setiap kelipatan 200. Sedangkan untuk mengetahui temperatur gas buang digunakan perangkat pengukur suhu dan termokopel. Termokopel dipasang pada manifold gas buang pada mesin generator. Laju alir gas yang digunakan adalah 0,2-0,3 liter per menit.

Hasil dari penujian ini dapat dilihat pada gambar 2 dan 3, dengan peningkatan pembebanan pada generator terjadi peningkatan torsi dan temperatur gas buang. Pada pembebanan 600 watt mengalami kenaikan yang tinggi kemudian mengalami penurunan kenaikan pada pembebanan 800 watt. Hal ini disebabkan pada saat pembebanan 800 watt mesin mengalami kekurangan laju aliran gas karena campuran bahan bakar gas dan udara tidak sempurana. Sehingga mesin mengalami kekurangan bahan bakar. Setelah dilakukan peningkatan laju alir bahan bakar gas maka pada

Tabel 2. Komposisi gas metana $\left(\mathrm{CH}_{4}\right)$ pada biogas umur 15 hari

\begin{tabular}{cccc}
$\begin{array}{c}\text { No. } \\
\text { Sampel }\end{array}$ & $\begin{array}{c}\text { Sebelum pemurnian } \\
\mathrm{CH}_{4}(\% \mathrm{~mol})\end{array}$ & $\begin{array}{c}\text { Setelah pemurnian } \\
\mathrm{CH}_{4}(\% \mathrm{~mol})\end{array}$ & Keterangan \\
\hline 1. & 42,467 & 75,352 & Volume gas sampler $50 \mathrm{ml}$ \\
2. & 38,025 & 73,055 & Volume gas sampler $50 \mathrm{ml}$ \\
3. & 41.005 & 75,331 & Volume gas sampler $50 \mathrm{ml}$ \\
\hline
\end{tabular}

Tabel 3. Hasil uji unjuk kerja Mesin Generator 220 (V)/ 1300 (watt)

\begin{tabular}{cccc}
\hline No. & $\begin{array}{c}\text { Beban } \\
(\text { Watt })\end{array}$ & $\begin{array}{c}\text { Torsi } \\
(\mathrm{Nm})\end{array}$ & $\begin{array}{c}\text { Temperatur } \\
\text { gas buang }\left({ }^{\circ} \mathrm{C}\right)\end{array}$ \\
\hline 1. & 200 & 0.2 & 220 \\
2. & 400 & 1 & 245 \\
3. & 600 & 2.3 & 380 \\
4. & 800 & 2.8 & 430 \\
5. & 1000 & 4.1 & 490 \\
\hline
\end{tabular}




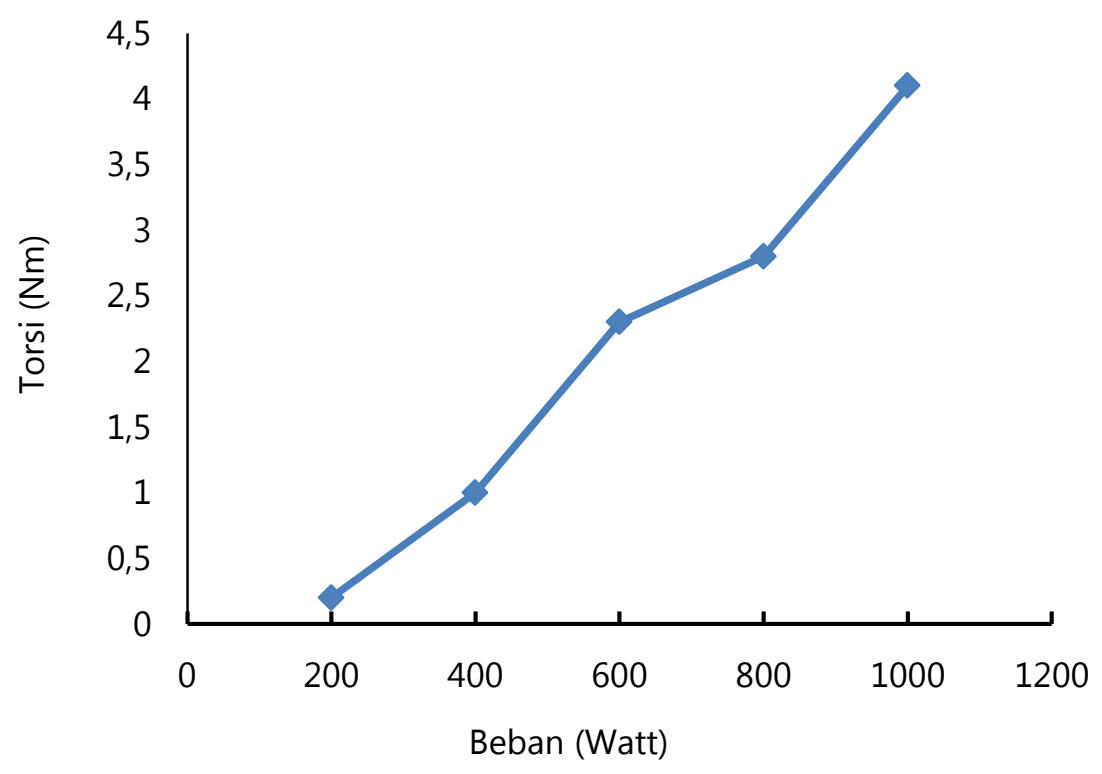

Gambar 2. Torsi versus Beban

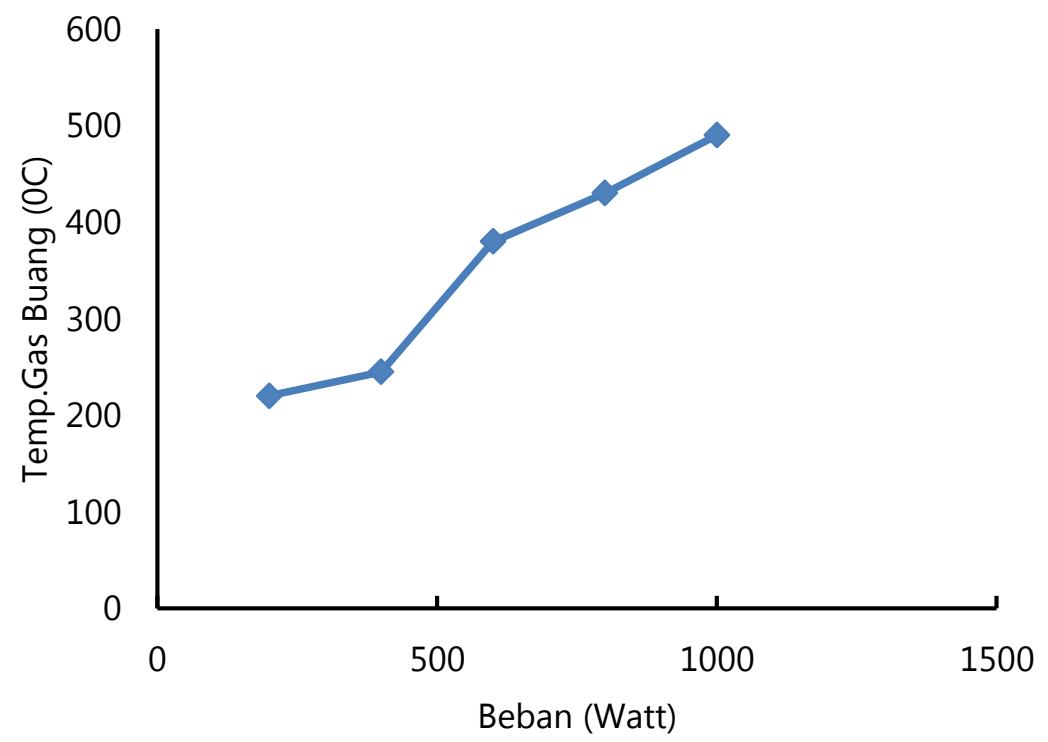

Gambar 3. Temperatur Gas Buang versus Beban

pembebanan 1000 watt mesin kembali menunjukkan kenaikan torsi yang tinggi.

Pada gambar 3, temperatur gas buang mengalami kenaikan sebanding dengan terjadinya kenaikan pembebanan pada mesin generator. Temperatur yang dihasilkan dari pembakaran gas metana ternyata sangat tinggi jika dibandingkan dengan menggunakan bahan bakar bensin. Gas metana mempunyai angka oktan 100 , lebih tinggi dari bensin yaitu 90 , sehingga proses pembakaran lebih sempurna dan menyebabkan temperatur gas buang pada bahan bakar metana lebih tinggi dari pada bensin. Secara mekanis peningkatan rasio kompresi juga menyebabkan kenaikan temperature gas buang.

\section{KESIMPULAN}

Biogas dengan kemurnian gas metana 75,352 (\% mol) dengan laju alir gas yang 
digunakan adalah 0,2-0,3 liter per menit, pada pengujian mesin generator 220 (V)/ 1300 (Watt), didapat hasil dengan pembebanan maksimal 1000 (watt) dengan torsi yang dihasilkan sebesar 4,1 $(\mathrm{Nm})$. Stabilitas torsi pada pengujian beban tetap tersebut hasilnya baik.

\section{DAFTAR PUSTAKA}

Anonim, (http://www.kolumus.fi/suomen.biokaasu k seskus/en/enperus.htm)

Hambali, R.D., Sperisa, D., Adrian, N., \&Paryanto., 2007. Pengaruh Kondisi Fermentasi Terhadap Yield Etanol pada Pembuatan Biogas dari Pati Garut. Gema Teknik. 2: 83-88

Haryati, T., 2006. Biogas: Limbah peternakan yang menjadi sumber energi alternatif. Jurnal Wartazoa, 16(3), pp.160-169.

Hullu, J. De., Maassen, J.I.W., Meel, \& Van, P.A, 2008, Comparing different biogas upgrading techniques, Eindhoven University of technology. Eindhoven.

Lin, K.Z. 2005, Design and Performance Analysis of Converted CNG Engine, Yangon Technological University, Departement of Mechanical Engineering, Yangon, Myanmar.

Mitzlaff, K.V. 1988. Engine for Biogas : Theory, modification, economic operation", Deutsches Zentrum Fur Technische Zusamenarbeit (GTZ) GmbH., Eschborn, Germany.

Monnet, F., 2003, An Introduction to anaerobic digestion of organic waste, Chem. Eng. J. 102: 171-184

Pellerin, R.A., Walker, L.P., Heisler, M.G. \& Farmer, G.S., 1988. Operation and performance of biogas-fueled cogeneration systems. Energy in agriculture, 6(4):295-310. 